\title{
Análise do Potencial de Indicação Geográfica: 0 caso do Polo Moveleiro de Marco (CE)
}

\author{
Analysis of the Potential of Geographical Indication: the case of The \\ Marco Furniture region
}

\author{
Márcio Nannini da Silva Florêncio ${ }^{1}$ \\ Maraiza Santana dos Santos ${ }^{1}$ \\ Francisco Sandro Rodrigues Holanda ${ }^{1}$ \\ Antonio Martins de Oliveira Júnior ${ }^{1}$ \\ Universidade Federal de Sergipe, São Cristóvão, SE, Brasil
}

\begin{abstract}
Resumo
O objetivo deste artigo é identificar o potencial do Polo Moveleiro de Marco (CE) para registro por indicação de procedência com base na norma brasileira (NBR 16536) da Associação Brasileira de Normas Técnicas (ABNT) publicada em 2016. A metodologia da pesquisa pautou-se em uma revisão bibliográfica e levantamento de dados junto ao banco de marcas e indicações geográficas brasileiro. Os resultados evidenciaram as características e o potencial do Polo Moveleiro de Marco em função da reputação e notoriedade, delimitação geográfica, signo, alianças, parcerias, análise do produto e cadeia produtiva e estrutura de gestão. Com base nos fatores analisados, percebeu-se que o polo moveleiro possui potencial para obter o registro de Indicação Geográfica (IG), mas ainda é necessário disseminar a cultura de propriedade intelectual entre os empreendedores da região. Sugerem-se recomendações para pesquisas futuras e os atores envolvidos.
\end{abstract}

Palavras-chave: Indicação Geográfica. Indústria Moveleira. Propriedade Intelectual.

\begin{abstract}
The objective of the article was to identify the potential of the Marco furniture region for registration by geographical indication based on the Brazilian standard (NBR 16536) published in 2016. The methodology consisted of a bibliographical review and data collection with the database of Brazilian brands and geographical indications. The results showed the characteristics and potential of the Marco Furniture region in terms of reputation and notoriety, geographical delimitation, sign, alliances and partnerships, product analysis and production chain and management structure. Based on the analyzed factors, it is believed that the furniture region has the potential to obtain the geographical indication register, but it is still necessary to disseminate the culture of intellectual property among the entrepreneurs of the region. The study presented recommendations for future research and the actors involved.
\end{abstract}

Keywords: Geographical Indication. Furniture industry. Intellectual Property.

Área Tecnológica: Indicação Geográfica. Propriedade Intelectual. 


\section{Introdução}

A Indicação Geográfica (IG) refere-se a um processo que identifica a notoriedade atribuída a um produto ou serviço tradicional, originário de um território cujas características são essenciais para sua origem geográfica. Segundo Medeiros e Passador (2015), esse ativo de propriedade intelectual pode ser usado como instrumento de proteção e valorização de produtos e serviços, permitindo agregação de valor, diferencial competitivo e promoção turística da região.

O registro de Indicação Geográfica (IG) vem crescendo nos últimos anos, os principais fatores para que um produto adquira certa notoriedade estão relacionados com o local de produção, em função do solo, do clima, da forma de produção e da colheita, ou com outras características que lhe confiram um diferencial. Essa especificidade tende a contribuir com a agregação de valor a esses produtos, o que pode gerar maior retorno financeiro aos atores envolvidos, com possíveis impactos no desenvolvimento territorial (MAIORKI; DALLABRIDA, 2015).

No Brasil, a IG é regulamentada por meio dos direitos e obrigações sobre propriedade industrial de acordo com a Lei n. 9.279, de 14 de maio de 1996, disciplinada no Título IV, nos artigos 176 a 182, que no seu parágrafo único, especificamente no artigo 182 determina que o Instituto Nacional da Propriedade Industrial (INPI) é responsável por estabelecer as condições para o registro de indicações geográficas, podendo ser registrada como Indicação de Procedência (IP) ou Denominação de Origem (DO). Essas espécies de IG foram definidas na legislação brasileira como:

Considera-se indicação de procedência o nome geográfico de país, cidade, região ou localidade de seu território, que se tenha tornado conhecido como centro de extração, produção ou fabricação de determinado produto ou de prestação de determinado serviço.

Considera-se denominação de origem o nome geográfico de país, cidade, região ou localidade de seu território, que designe produto ou serviço cujas qualidades ou características se devam exclusiva ou essencialmente ao meio geográfico, incluídos fatores naturais e humanos. (BRASIL, 1996, art. 177, 178)

Mais recentemente, o INPI estabeleceu a Instrução Normativa n. 25, de 21 de agosto de 2013, discriminando todos os documentos necessários e outras condições para solicitar o registro de IG. Aliado a isso, é oportuno ressaltar que Associação Brasileira de Normas Técnicas (ABNT) publicou a norma NBR 16536 de 2016 que fornece orientações para estruturação de indicações geográficas. A norma auxilia na elaboração da documentação que pode subsidiar no pedido dessa propriedade industrial, contribuindo com empresários, associações, produtores $e$ outros atores com interesse no tema.

A IG é considerada uma propriedade industrial, coletiva e exclusiva a produtores de determinado local, sendo um de seus principais objetivos o desenvolvimento econômico do território, por meio de vinculação do produto, sua qualidade e especificidade em relação ao território onde é produzido (PIMENTEL, 2013).

A Indicação Geográfica obtida por um produto ou serviço está relacionada ao reconhecimento imaterial (saber-fazer-tradição, costumes, práticas de produção) a ele associados, individualizando-os perante os seus semelhantes e gerando o direito de comercialização reservados aos produtos da região de abrangência (NIEDERLE, 2014). 
O registro de IG apresenta-se como um ponto de partida para fomentar novas alianças entre turismo, serviços e demais setores de uma região. Permite, ainda, alguns benefícios como a proteção ao patrimônio, o desenvolvimento rural, a promoção e facilidades de exportação de produtos ou serviços (KAKUTA et al. 2006). Destaca-se a importância da IG no âmbito de políticas públicas para uma região, inclusive para as pessoas envolvidas e para o crescimento econômico de uma associação ou cooperativa de um determinado território.

Atualmente existem 104 pedidos de IG no INPI, seja na espécie de Indicação de Procedência (IP) seja na Denominação de Origem (DO), sendo no total 58 registradas com o selo de autenticidade, assim representando várias regiões do Brasil. Entre as IGs ressaltam-se os vinhos finos, do Vale dos Vinhedos (RS), o Café do Cerrado (MG), a Carne do Pampa Gaúcho (RS), a Cachaça de Paraty (RJ), o Camarão da Costa Negra (CE), além de outros pedidos depositados.

Alguns estados do Brasil, como o Ceará, vêm se destacando e apresentando grande potencial para IG em determinados territórios. O mapeamento realizado pelo Ministério da Agricultura, Pecuária e Abastecimento (MAPA) tem evidenciado um número significativo de lugares no Ceará associados a produtos agropecuários, como café, mel, queijo, cajuína, cachaça, com potencial para marcas coletivas ou indicações geográficas, conforme pode ser observado na Figura 1. Ressalta-se que foi na região do litoral Oeste do Ceará, formada pelos municípios de Itarema, Acaraú, Cruz e Jijoca de Jericoacoara, onde com a produção de camarões obteve o primeiro certificado de denominação de origem emitido, no mundo, para crustáceo (SNA, 2014).

Figura 1 - Localizações do Território Cearense com signos distintos registrados e potenciais produtos

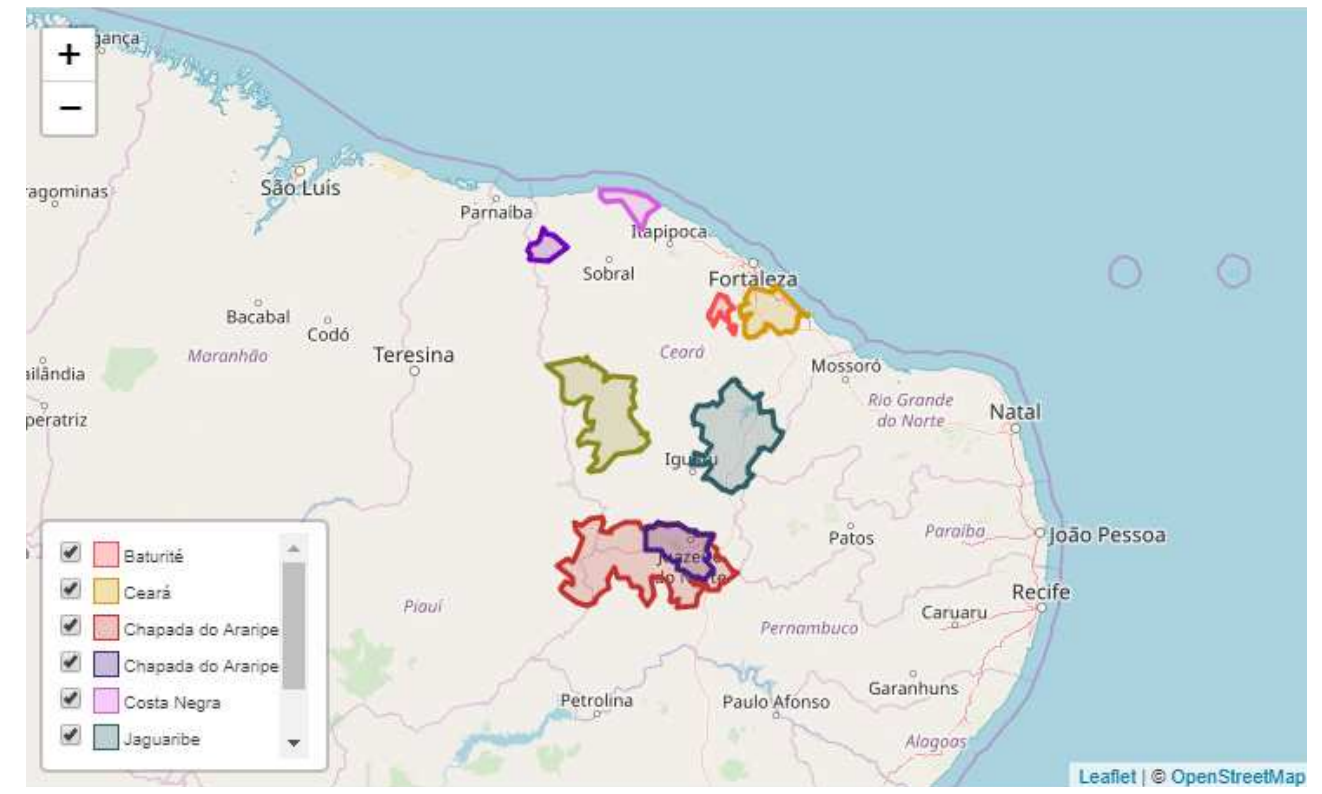

Fonte: Brasil (2019)

O Estado do Ceará vem apresentando desenvolvimento e crescimento econômico em regiões cujos produtores se reúnem em forma de associações ou cooperativas. Nesse contexto, convém destacar os Fabricantes Associados de Marco (FAMA) com 17 empresas filiadas atuando no Polo Moveleiro de Marco que se tornou famoso pela fabricação de móveis residenciais, produzindo estofadas, móveis salas de jantar, dormitórios e outros móveis elaborados com madeira, fibras naturais, vidro, ferro e alumínio (FERRAZ; GOBB; LIMA, 2011). 
Dessa forma, o presente estudo teve o objetivo de identificar o potencial do Polo Moveleiro de Marco (CE) para proteção por indicação de procedência com base na norma brasileira (NBR 16536) da ABNT publicada em 2016.

\section{Metodologia}

A metodologia adotada neste estudo baseia-se em pesquisa bibliográfica a partir de informações secundárias obtidas em periódicos, dissertações, jornais de circulação regional e em outras referências. Além disso, para atingir o objetivo desta pesquisa, foi consultada a norma brasileira de orientações para estruturação de Indicação Geográfica para produto (NBR 16536) da ABNT publicada em 2016. A partir dessa norma, foram extraídos seis fatores relevantes que conduziram o processo de análise das informações para evidenciar o potencial de indicação por procedência do Polo Moveleiro de Marco. A Figura 2 apresenta os fatores extraídos da norma brasileira.

Figura 2 - Fatores relevantes para obtenção de uma indicação por procedência

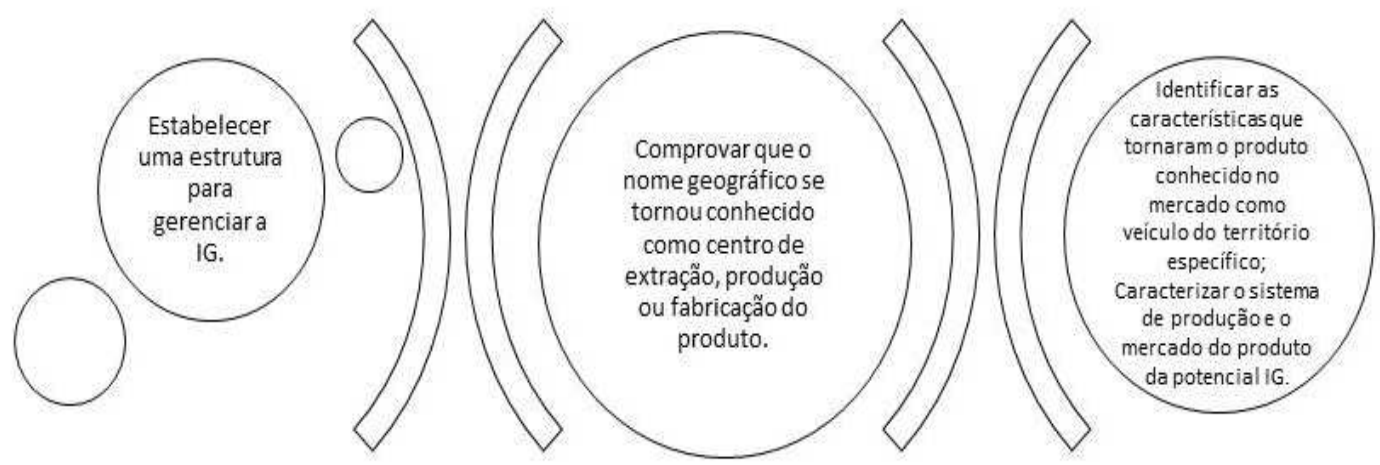

\section{Estrutura de gestão}

Notoriedade e reputação

\section{Produto e cadeia} produtiva

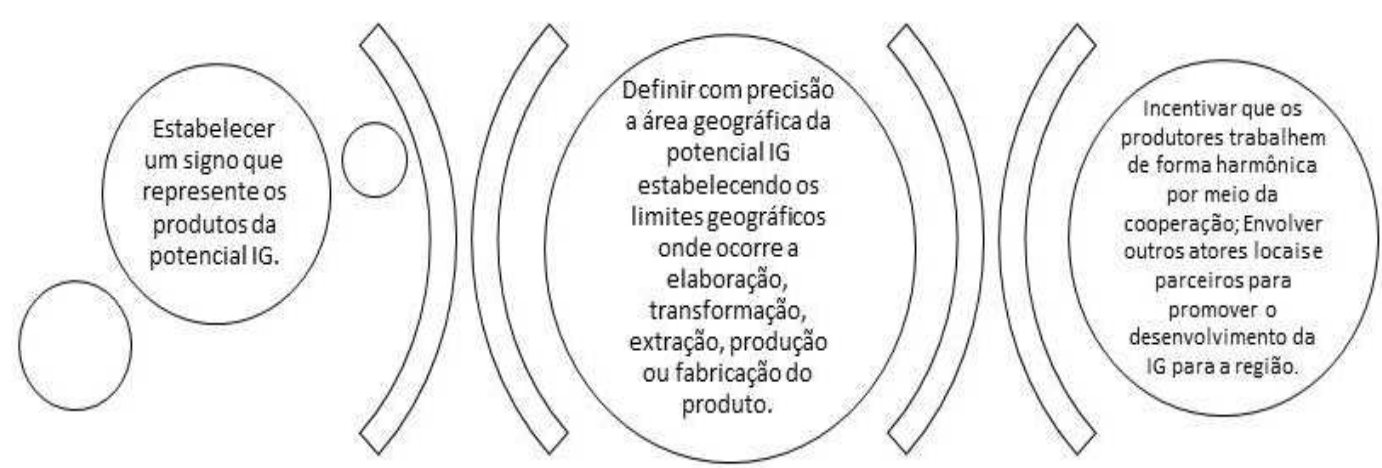

Signo

Delimitação geográfica

Alianças e parcerias

Fonte: Adaptada da ABNT (2016)

Destaca-se que, no fator signo, foi realizado um levantamento dos registros de marcas das empresas filiadas à FAMA e da própria associação junto à base de dados do INPI, disponível no link: (http://www.inpi.gov.br/). A pesquisa foi conduzida no campo titular, utilizando-se o Cadastro Nacional da Pessoa Jurídica (CNPJ) para recuperação das informações. 


\section{Resultados e Discussão}

Os resultados e as discussões sobre o potencial de indicação geográfica do Polo Moveleiro de Marco no Ceará foram divididos em duas seções que descrevem, de um lado, as principais características do polo moveleiro e, de outro lado, destacam o seu potencial de IG, considerando fatores como notoriedade e reputação, delimitação geográfica, signo, alianças, parcerias, análise do produto, cadeia produtiva e estrutura de gestão.

\subsection{Caracterização do Polo Moveleiro de Marco (CE)}

O Polo Moveleiro de Marco (CE) começou suas atividades nos anos de 1990 com incentivo do governo do estado do Ceará por meio de uma política de desenvolvimento do interior que visava ao estímulo das indústrias locais (LINHARES, 2017). A região de Marco (CE) é reconhecida por ser uma potência econômica devido ao APL existente, passando a ser mais reconhecida como um dos maiores polos moveleiros do Norte e Nordeste do país (ALVARENGA et al., 2013). Assim, para os autores, os Arranjos Produtivos Locais (APLs) são entendidos como aglomerações com territórios definidos e agentes envolvidos em sua constante transformação que possuam atividades de interesse em comum e também uma conexão entre si. Os APLs possuem um caráter inovativo, evolutivo e dispõem de relações de interdependência entre os atores. Há também uma boa articulação com seus pares/parceiros e clientes em potencial, além de terem um vínculo consistente.

Nesse sentido, Scipião (2004) aponta três razões que explicam o surgimento do Arranjo Produtivo Local moveleiro de Marco, a saber:

a) O programa de Compras Governamentais iniciado em 1987 que possibilitou que pequenas serrarias locais se reunissem em forma de associação para atender à demanda da Secretaria de Educação por carteiras escolares.

b) A posição geográfica do Município de Marco que fica no caminho da "rota da madeira" proveniente do Pará com destino a Fortaleza e demais estados nordestinos.

c) A participação de empresário que incentivou a criação de estabelecimentos comerciais e unidades de fabricação de móveis na cidade.

As razões encontradas na literatura para o surgimento do APL Moveleiro de Marco parecem convergir em três fatores principais: incentivo governamental, posição geográfica e visão empreendedora. Aliado a isso, Gobb (2008) ressalta que existem laços familiares entre os empreendedores do setor, o que pode explicar, pelo menos em parte, o interesse de cooperação entre si. Inicialmente o arranjo de móveis se localizava nos municípios de Marco e Bela Cruz, sendo que apenas Marco conseguiu atingir um desenvolvimento sustentável, que, por meio da cooperação entre as empresas e o seu nível de proximidade, resultou em um polo moveleiro (LIMA, 2007).

A Associação dos Moveleiros de Marco (AMMA) foi criada em 1996 sendo reativada em 2001. Em 2004, as empresas se filiaram ao Sindicato das Indústrias Mobiliárias do Estado do Ceará (SINDMÓVEIS), com o intuito de conseguir mais benefícios para a indústria local. Em 2006, a AMMA, em parceria com o SEBRAE/CE, implantou o programa de Gestão Estratégica 
Orientada para Resultados (GEOR) com o propósito de desenvolver o APL (LIMA, 2007). Tudo isso culminou, em 2008, na elaboração do plano de desenvolvimento do Arranjo Produtivo Local de móveis do Marco Ceará, elaborado pela AMMA e o Núcleo Estadual de Apoio aos APLs do Estado do Ceará com representantes do SEBRAE/CE, do Instituto Euvaldo Lodi (IEL) e da Secretaria das Cidades do Governo do Estado do Ceará.

Mais recentemente, a associação encontra-se sob a denominação de Fabricantes Associados de Marco (FAMA) e conta com 17 empresas filiadas (LINHARES, 2017). Segundo o Instituto de Pesquisa e Estratégia Econômica do Ceará (IPECE, 2015), o APL de Móveis de Marco possui 36 empresas legalizadas com faturamento anual de $\mathrm{R} \$ 180.000 .000,00$, sendo reconhecido como o $8^{\circ}$ polo moveleiro do Brasil. O Polo Moveleiro de Marco possui um amplo mercado consumidor atendendo desde o próprio município até o comércio exterior. No mercado nacional possui atuação em quase todo o território nacional com predominância para as regiões Norte e Nordeste. No mercado externo, comercializa para países como México, Porto Rico, Estados Unidos, Portugal e Alemanha (GOBB, 2008).

O APL moveleiro de Marco é composto de indústrias especializadas em móveis residenciais produzindo estofados, salas de jantar, dormitórios e móveis para jardins, elaborados com madeira, fibras naturais, vidro, ferro e alumínio. A produção de madeira maciça agrega qualidade ao produto conferindo o diferencial dos seus móveis (FERRAZ; GOBB; LIMA, 2011).

\subsection{O Potencial do Polo Moveleiro de Marco (CE) para Registro por Indicação de Procedência}

Uma IG pode ser considerada como uma ferramenta para o desenvolvimento econômico em uma determinada região. Consequentemente, é possível verificar que por meio disso ocorre a agregação de valor ao produto $e$ o aumento das vendas para que seja possível a captação de novos mercados (PELLIN, 2019; BACELAR et al., 2020). Para que haja uma Indicação de Procedência, é necessário que o nome geográfico do país, cidade, região ou localidade e seu território sejam reconhecidos e tenham potencial como um centro de atração, produção ou fabricação de um determinado produto ou serviço (BRASIL, 1996).

O potencial do APL moveleiro de Marco foi investigado à luz da norma brasileira (NBR 16536) publicada em 2016. Com base na citada norma, foi possível perceber seis fatores necessários para obtenção de uma indicação por procedência, a saber: reputação e notoriedade, delimitação geográfica, signo, alianças, parcerias, análise do produto, cadeia produtiva e estrutura de gestão.

De acordo com a Norma Brasileira NBR 16536 (ABNT, 2016), a reputação e notoriedade indicam a comprovação de que o nome geográfico se torne conhecido como um centro de extração, produção ou fabricação do produto, que seguem os elementos históricos de construção do renome, que podem ser: I) análise da evolução do produto na área geográfica delimitada; II) marcos históricos da construção do território na ótica do potencial IG; III) elementos geográficos que qualificam o produto da região; IV) elementos sobre o "sabe-fazer" local associado ao produto; V) tradição; VI) turismo associado ao produto; VII) paisagem estática, dinâmica e construída; e VIII) outros elementos associados à reputação ou à notoriedade do produto na região. 
A cidade de Marco é reconhecida pela fabricação de móveis residenciais, sendo considerada um dos mais importantes polos moveleiros do Norte e Nordeste do Brasil (CAMPOS, 2010; DIÁRIO DO NORDESTE, 2017) e $8^{\circ}$ maior APL de móveis do país (IPECE, 2015). Marco é o principal polo moveleiro do Ceará, destacando-se pela fabricação de móveis como uma de suas principais atividades econômicas (ALVARENGA et al., 2013). Ademais, a AMMA (2008) destaca que o município de Marco tornou-se referência no setor moveleiro, gerando emprego e renda para a comunidade local e outros municípios vizinhos. Em 2012, o APL de móveis gerou 1.110 empregos diretos, representando 37\% dos empregos formais do munícipio (BRASIL, 2015).

O APL de móveis de Marco tem sido objeto de diversas pesquisas acadêmicas (SCIPIÃO, 2004; GOBB, 2008; ALVARENGA et al., 2013; TAHIM; ARAÚJO JÚNIOR, 2015; LINHARES, 2017; NOGUEIRA FILHO et al., 2017) em função de sua relevância econômica e social para o município, estado, região e, consequentemente, para o país.

A delimitação geográfica, segundo a Norma Brasileira NBR 16536 (ABNT, 2016), significa que a área geográfica da potencial IG apresente com precisão os limites geográficos nas quais existam as condições que possibilitem a elaboração, a transformação, a extração, a produção $e$ a fabricação do produto, mantendo suas características diferenciadas.

O município de Marco, fundado em 22 de novembro de 1951, apresenta uma extensão territorial de $583 \mathrm{~km}^{2}$ com altitude de 40 metros acima do mar e tem aproximadamente 26.484 habitantes com 35 empresas pertencentes ao segmento moveleiro (IPECE, 2015). O município situa-se na Região Noroeste do Estado do Ceará, a 234 km da capital Fortaleza. Marco localiza-se dentro da abrangência do baixo Acaraú e limita-se ao Norte com o município de Bela Cruz, ao Sul com os munícipios de Morrinhos e Senador Sá, ao Leste com o munícipio de Acaraú e ao Oeste com Granja (LINHARES, 2017). O mapa do munícipio de Marco/Ceará pode ser observado na Figura 3.

Figura 3 - Mapa do Município de Marco Ceará

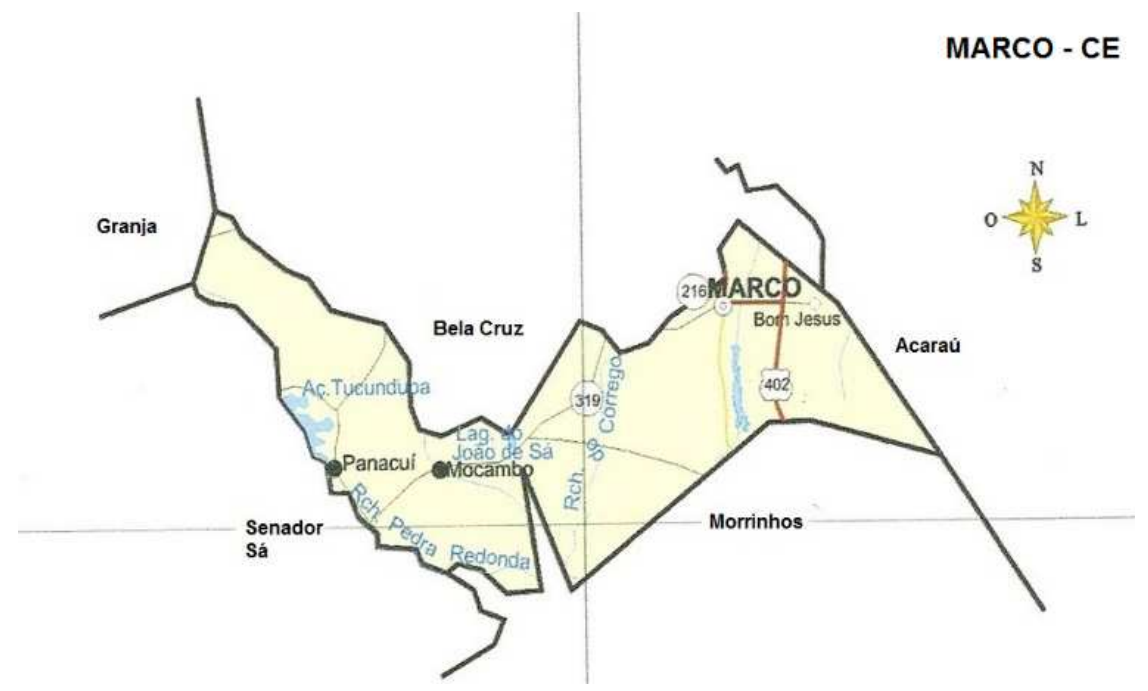

Fonte: Adaptada do IPECE (2015)

O APL de Móveis de Marco apresenta um portfólio diversificado de produtos, destacando-se pela produção de estofados, móveis para a sala de jantar, móveis para a sala de estar, armários de cozinha, móveis elaborados com Ratan e alumínios para serem decorados em varandas, vidraçarias, etc. (AMMA, 2008). Uma forte característica dos produtos do APL é a fabricação 
de móveis com madeira maciça. Marco situa-se na "rota da madeira", o que favoreceu a aquisição de matéria-prima (madeira) advinda de Belém com preços vantajosos em relação a outras regiões do país (GOBB, 2008).

Contundo, para garantir a autossuficiência do APL, a Empresa Brasileira de Pesquisa Agropecuária (EMBRAPA) Florestas e a EMBRAPA Agroindústria Tropical, com apoio financeiro do Banco do Nordeste e do Governo do Estado do Ceará, desenvolveram um projeto de cultivo de 42 espécies de plantas arbóreas e alguns híbridos com potencial moveleiro (EMBRAPA, 2014; 2017). Em adição, Nogueira Filho et al. (2017) mostraram ser economicamente viável a produção de eucalipto no Polo Moveleiro de Marco.

Os principais insumos usados na cadeia produtiva de Marco são madeira, compensado, MDF, tintas, verniz, tecidos, espuma e ferragens. As empresas com um porte maior adquirem madeira, tecidos e tintas diretamente de fornecedores situados nas Regiões Sul, Sudeste e principalmente Norte. Por outro lado, as empresas de pequeno porte obtêm seus insumos em sua maioria em madeireiras e em lojas varejistas de Fortaleza (AMMA, 2008). Scipião (2004) verificou que na cidade existem lojas de conexões para tubulações e material elétrico para manutenção de máquinas, sendo fácil conseguir profissionais para realizar serviços especializados como enrolar motores elétricos, torneiros mecanismos, entre outros.

O objetivo dos Signos é diferenciar bens e apresentar a sua origem comercial. Assim, caracterizar um bem (produto ou serviço) significa comprovar no mercado e para o consumidor, que um bem é diferente de outro de mesma quantidade e espécie em face de sua origem, de suas especialidades ou de sua qualidade (VIEIRA et al., 2014: SAMPAIO et al., 2020).

Apenas $17,6 \%$ das empresas filiadas à FAMA possuem suas marcas protegidas junto ao INPI. Foi observado ainda que o APL não apresenta uma marca coletiva que identifique os produtos fabricados no município de Marco. Isso, por um lado, reforça a importância de buscar uma proteção por indicação geográfica, mas, por outro, ressalta a necessidade crescente de disseminar a cultura de propriedade intelectual entre os empresários do setor. A proteção dos ativos intangíveis assegura que terceiros não possam explorar as criações das empresas do APL, assegurando indenizações e proibições nos casos de uso indevido.

A Fabricantes Associados de Marco (FAMA), implementou o planejamento estratégico organizando um conjunto de ações sistemáticas para o crescimento da associação e, consequentemente, de todo o Polo Moveleiro da região. A associação é responsável por prospectar investimentos e incentivos governamentais para o arranjo, além de agendar capacitações, entre outras atividades (AMMA, 2008). Essa associação tem favorecido o trabalho coletivo e a troca de informações, de experiências e de conhecimentos técnicos, o que pode contribuir para o amadurecimento dos empresários do Polo de Marco.

O APL de Móveis de Marco foi desenvolvido, em grande parte, por recursos próprios e por meio de ações de diversos parceiros que atuaram para potencializar o arranjo. Entre esses atores, destaca-se o Serviço Brasileiro de Apoio às Micro e Pequenas Empresas (SEBRAE), o Serviço de Aprendizagem Industrial (SENAI), a Empresa Brasileira de Pesquisa Agropecuária (EMBRAPA), os Fabricantes Associados de Marco (FAMA), o Sindicato das Indústrias do Mobiliário no Estado do Ceará (SINDMÓVEIS), o Instituto Euvaldo Lodi (IEL) e os Governos Estadual e Municipal de Marco, em especial o Núcleo Estadual de Apoio aos APLs e a secretaria das cidades (AMMA, 2008). Outro ponto importante é que o APL de móveis de Marco possui como característica 
marcante o forte espírito de cooperação entre as empresas, principalmente por meio da troca de experiências e de saberes (GOBB, 2008).

No caso da inovação, é importante destacar a criação dos novos produtos, a via mais comum entre os integrantes do arranjo é a utilização do "projeto híbrido", ou seja, são realizadas pequenas adaptações e ajustes nos modelos a serem elaborados, de acordo com o maquinário existente nas fábricas. Para tanto, emprega-se a "engenharia de reverso", ou seja, o trabalhador desmonta o produto para aprender como ele é confeccionado. Verificou-se que os profissionais do APL vêm conseguindo elaborar cópias bem-sucedidas (SCIPIÃO, 2004).

Outro método também utilizado para inovação de produtos consiste no uso de novos materiais para compor o produto final. O "MDF é o insumo mais difundido no setor, por permitir melhor maleabilidade no uso, implicando em redução de desperdício de material" (SCIPIÃO, 2004, p. 66). Em relação à tecnologia, o Polo de Marco em sua produção tem o apoio de maquinários que são comprados na sua grande maioria (95\%) no Sul do Brasil. Essas tecnologias são importadas da Europa, disponibilizando, assim, base e treinamento para a mão de obra no setor (SCIPIÃO, 2004).

Estudos que investigam o potencial de indicações geográficas no território brasileiro têm aumentado significativamente (SOUZA et al., 2015; REZENDE; SILVA; DANIEL, 2017; CARVALHO; RIBEIRO; SANTOS, 2018; AVENI et al., 2018; MARQUES et al., 2019; PIRES; SANTOS, 2019; BACELAR et al., 2020; SAMPAIO et al., 2020). Esses estudos têm avaliado os fatores que potencializam que determinada região obtenha o selo de IG. Notoriedade, reputação, características do produto e delimitação geográfica são fatores frequentemente adotados nos trabalhos, enquanto os aspectos históricos do produto, cadeia produtiva, mercado, marca e estrutura de gestão, são usados em menor grau. Comparativamente a esses estudos, o presente trabalho reúne os fatores já definidos e acrescenta as alianças e as parcerias na análise dos dados.

As alianças e as parcerias são fatores relevantes para uma indicação geográfica, uma vez que podem gerar tecnologias e inovações. Essas alianças e parcerias associadas a uma estrutura de gestão fornecem o apoio necessário para o desenvolvimento e continuidade da IG. Valente et al. (2013) apontaram que os quesitos mínimos necessários para início do processo de registro de IG correspondem aos fatores humanos e naturais da delimitação geográfica como sabe-fazer, tradição, tipicidade, clima, solo, vegetação e relevo. Além disso, o fator notoriedade para diferenciação do produto também é destacado como essencial.

Marques et al. (2019) destacaram que a indicação de procedência ultrapassa as questões econômicas e pode promover a melhoria das condições de vida da população, o fortalecimento dos produtores, o reconhecimento pela tradição na qualidade do produto e o estímulo à aprendizagem de gerações atuais. Nessa linha, o selo de IG promove o reconhecimento nacional e internacional, tornando os produtos ou os serviços mais competitivos em relação a sua comercialização (AVENI et al., 2018).

\section{Considerações Finais}

Este estudo buscou identificar o potencial de Indicação Geográfica do Polo Moveleiro de Marco em função da notoriedade e reputação, delimitação geográfica, produto, cadeia produtiva, signo, estrutura de gestão, alianças e parceiras. Esses seis fatores foram extraídos da NBR 16536, 
publicada pela ABNT em 2016, e possibilitaram a condução do processo de identificação da potencial indicação de procedência.

De maneira geral, o Polo Moveleiro de Marco atende a quase todos os fatores levantados, com exceção do fator signo que mostrou que boa parte dos empresários do arranjo não faz a proteção de suas marcas. Em razão disso, sugere-se a realização de cursos e treinamentos para os atores locais com o objetivo de informá-los e de sensibilizá-los sobre a importância da propriedade intelectual e seus mecanismos de proteção.

Ademais, destaca-se que o Polo Moveleiro de Marco possui potencial para obter a indicação de procedência. Contudo, é importante que inicialmente seja disseminada a cultura de propriedade intelectual entre os empreendedores locais com vistas a capacitá-los para aproveitar e desenvolver todo o potencial da IG. Em outras palavras, políticas públicas de incentivo, apoio e conscientização quanto aos benefícios da IG tornam-se necessárias para a comunidade local. Assim, uma indicação de procedência para o Polo Moveleiro de Marco estimula o desenvolvimento local, promovendo o reconhecimento e o fortalecimento dos produtos da região, o que pode produzir ganhos econômicos e sociais.

O estudo contribui com as discussões sobre potenciais indicações geográficas no Brasil ao abordar o caso do Polo Moveleiro de Marco. Novos estudos precisam ser conduzidos na região, a fim de apoiar o processo de condução de uma possível indicação de procedência. Por exemplo, projetos de extensão poderiam ser realizados para reunir a documentação necessária e solicitar o registro junto ao INPI, ou mais estudos poderiam avaliar os fatores que influenciam o produto para obter o selo de IG. Sugere-se, ainda, que sejam realizadas pesquisas futuras de cunho empírico com o intuito de utilizar os fatores levantados como ferramenta de avaliação de potenciais Indicações de Procedência.

\section{Referências}

ABNT - ASSOCIAÇÃO BRASILEIRA DE NORMAS TÉCNICAS. NBR 16536: Indicação Geográfica - Orientação para estruturação de Indicação Geográfica para produto. Rio de Janeiro: ABNT, 2016. p. 17.

ALVARENGA, R. A. M. et al. Arranjo Produtivo Local e Desenvolvimento Sustentável: uma Relação Sinérgica no Município de Marco (CE). Revista de Administração Mackenzie, [s.l.], v. 14, n. 5, p. 15-43, set.-out. 2013.

AMMA - ASSOCIAÇÃO DOS MOVELEIROS DE MARCO. Plano de Desenvolvimento do Arranjo Produtivo Local de Móveis do Marco - Ceará. [S.l.]: Núcleo Estadual de Apoio aos Arranjos Produtivos Locais, 2008.

AVENI, A. et al. O Potencial de Indicação Geográfica do Mel da Ride. Cadernos de Prospecção, Salvador, v. 11, n. 5, Edição Especial, VIII ProspeCT\&I, p. 1.792-1.804, 2018. DOI: https://doi.org. org/10.9771/cp.v11i5.27064.

BACELAR, A. C. B. et al. Análise do potencial de indicação geográfica para o café do planalto de Vitória da Conquista/BA. Revista INGI - Indicação Geográfica e Inovação, [s.l.], v. 4, n. 3, p. 875-888, 2020. 
BRASIL. Ministério do Desenvolvimento e Comércio Exterior (MIDIC), Instituto Nacional da Propriedade Industrial (INPI). Lei n. 9.279, de 14 de maio de 1996 - Lei da Propriedade Industrial. Brasília, DF: MIDIC; INPI, 1996.

BRASIL. Ministério da Agricultura, Pecuária e Abastecimento (MAPA). Mapa Interativo - Signos Distintivos Registrados e Produtos Potenciais. 2019. Disponível em: http://www.agricultura.gov. br/assuntos/sustentabilidade/indicacao-geografica/mapa-interativo. Acesso em: 16 dez. 2018.

BRASIL. Ministério do Trabalho e Emprego (MTE). Relação Anual de Informações Sociais. 2015. Disponível em: http://portal.mte.gov.br/portal-mte/. Acesso em: 26 ago. 2018.

BRASIL. Lei n. 9.279, 14 de maio de 1996. Regula direitos e obrigações relativos à propriedade Industrial. [1996]. Disponível em: http://www.planalto.gov.br/ccivil_03/leis/L9279.htm. Acesso em: 27 dez. 2018.

CAMPOS, L. H. Polo moveleiro de Marco é reconhecido como um dos maiores do Norte e Nordeste. 2010. Disponível em: https:/www.logicainfo.com.br/noticias/111/polo-moveleiro-demarco-e-reconhecido-como-um-dos-maiores-do-norte-e-nordeste./. Acesso em: 16 dez. 2018.

CARVALHO, R. S.; RIBEIRO, M. J. B.; SANTOS, M. J. C. Potencialidade para concessão da indicação geográfica do bordado boa-noite na ilha do Ferro/AL. Revista GEITEC - Gestão, Inovação e Tecnologias, [s.l.], v. 8, n. 1, p. 4.283-4.291, 2018. DOI: 10.7198/geintec.v8i1.1261.

DIÁRIO DO NORDESTE. SDE destaca potencial do Polo Moveleiro de Marco. Fortaleza, 24 nov. 2017. Disponível em: http://diariodonordeste.verdesmares.com.br/editorias/negocios/sdedestaca-potencial-do-polo-moveleiro-de-marco-1.1855521. Acesso em: 16 dez. 2018.

EMBRAPA - EMPRESA BRASILEIRA DE PESQUISA AGROPECUÁRIA. Madeira para móveis no semiárido. 2014. Disponível em: https:/www.embrapa.br/busca-de-noticias/-/noticia/2218356/ madeira-para-moveis-no-semiarido. Acesso em: 19 dez. 2018.

EMBRAPA - EMPRESA BRASILEIRA DE PESQUISA AGROPECUÁRIA. Teste e seleção de espécies arbóreas para a Indústria do Polo Moveleiro de Marco, CE. 2017. Disponível em: https://ainfo.cnptia.embrapa.br/digital/bitstream/item/171350/1/FFC17004.pdf. Acesso em: 19 dez. 2018.

FERRAZ, S. F. S.; GOBB, R. L.; LIMA, T. C. B. Teoria do Capital Social: Um Estudo no Cluster Moveleiro de Marco (CE). Contextus, [s.l.], v. 9, n. 2, p. 79-85, jul.-dez. 2011.

GOBB, R. L. Arranjos Produtivos Locais na Perspectiva da Teoria do Capital Social: um Estudo no APL Moveleiro de Marco/CE. 2008. 180f. Dissertação (Mestrado em Administração) Universidade Federal do Ceará, Fortaleza, 2008.

IPECE - INSTITUTO DE PESQUISA E ESTRATÉGIA ECONÔMICA DO CEARÁ. Anuário estatístico do Ceará. 2015. Disponível em: http://www.ipece. CE.gov.br/publicações/anuário/ anuário2015/. Acesso em: 26 ago. 2018.

INPI - INSTITUTO NACIONAL DA PROPRIEDADE INDUSTRIAL. Instrução Normativa n. 25, 21 de agosto de 2013. Estabelece as condições para o registro das indicações geográficas. 2013. Disponível em: http://www.inpi.gov.br/legislacao-1/in_25_21_de_agosto_de_2013.pdf. Acesso em: 27 jan. 2019.

KAKUTA, S. M. et al. Indicações geográficas: guia de respostas. Porto Alegre: SEBRAE/RS, 2006. 
LIMA, F. M. C. Móveis de Marco: um sonho que ultrapassou fronteiras. In: SEBRAE - SERVIÇO BRASILEIRO DE APOIO ÀS MICRO E PEQUENAS EMPRESAS. Histórias de Sucesso. Fortaleza: Sebrae, 2007.

LINHARES, F. J. M. Capacidade Absortiva e Capacidade de Inovação: o caso do Arranjo Produtivo Local de Móveis no Interior do Ceará. 2017. 112 f. Dissertação (Mestrado em Administração). Universidade do Vale do Itajaí, Biguaçu, 2017.

MAIORKI, G. J.; DALLABRIDA, V. R. A indicação geográfica de produtos: um estudo sobre sua contribuição econômica no desenvolvimento territorial. Interações, Campo Grande, v. 16, n. 1, p. 13-25, 2015. DOI: https://doi.org.org/10.1590/151870122015101.

MARQUES, B. N. et al. Artefatos de Couro de Ipirá: potencial de Indicação Geográfica no território da Bacia do Jacuípe - Bahia. Cadernos de Prospecção, Salvador, v. 12, n. 5, Edição Especial, IX ProspeCT\&I, p. 1.598-1.611, 2019. DOI: https://doi.org.org/10.9771/cp.v12i5\%20Especial.31018.

MEDEIROS, M. L.; PASSADOR, J. L. Indicações geográficas e turismo: possibilidades no contexto brasileiro. Revista Perspectivas Contemporâneas, [s.l.], v. 10, n. 3, p. 56-79, set.-dez. 2015.

NIEDERLE, P. A. Desenvolvimento, instituições e mercados alimentares: os usos das indicações geográficas. Desenvolvimento Regional em Debate, [s.l.], v. 4, p. 21-43, 2014.

NOGUEIRA FILHO, F. P. et al. Viabilidade econômica da produção de eucalipto no polo moveleiro de Marco - Ceará. Revista Pecege, [s.l.], v. 3, n. 4, p. 22-34, 2017.

PELLIN, V. P. Indicações Geográficas e desenvolvimento regional no Brasil: a atuação dos principais atores e suas metodologias de trabalho. Interações, Campo Grande, [s.l.], v. 20, n. 1, p. 63-78, 2019. DOI: https://doi.org/10.20435/inter.v20i1.1792.

PIMENTEL, L. O. Os desafios dos aspectos legais na prática de estruturação das Indicações Geográficas. In: DALLABRIDA, V. R. (org.). Território, identidade territorial e desenvolvimento regional: reflexões sobre Indicação Geográfica e novas possibilidades de desenvolvimento com base em ativos com especificidade territorial. São Paulo: LiberArs, 2013. p. 135-143.

PIRES, P. B. S.; SANTOS, V. M. L. Potencial de indicação geográfica do acarajé baiano. Revista INGI - Indicação Geográfica e Inovação, [s.l.], v. 3, n. 3, p. 432-435, 2019.

REZENDE, A. A.; SILVA, M. S.; DANIEL, L. P. Indicação Geográfica: uma via para o crescimento econômico para Nazaré das Farinhas e Maragogipinho, Bahia. Revista Paranaense de Desenvolvimento, [s.l.], v. 38, n. 132, p. 55-76, 2017.

SAMPAIO, G. et al. Farinha de mandioca de Buerarema, Bahia: potencialidades para registro como indicação geográfica. Revista INGI - Indicação Geográfica e Inovação, [s.l.], v. 4, n. 3, p. 889902, 2020.

SCIPIÃO, T. T. Política Industrial para Promoção de Arranjos Produtivos Locais: um Estudo de Caso em Marco - Ceará. 2004. 116f. Dissertação (Mestrado em Políticas Públicas e Sociedade) Universidade do Estado do Ceará, Fortaleza, 2004.

SNA - SOCIEDADE NACIONAL DA AGRICULTURA. A Lavoura, [s.l.], v. 117, n. 705, 2014.

SOUZA, J. M. L. et al. Potencial de IG da farinha de mandioca de Cruzeiro do Sul. Cadernos de Prospecção, Salvador, v. 8, n. 1, p. 182-191, 2015. DOI: https://doi.org.org/10.9771/s. cprosp.2015.001.020. 
TAHIM, E. F.; ARAÚJO JÚNIOR, I. F. Mecanismos de aprendizagem, cooperação e inovação em aglomerações produtivas: o caso da indústria de móveis de Marco. Ensaios FEE, [s.l.], v. 36, n. 2, p. 541-568, 2015.

VALENTE, M. E. R. et al. O processo de reconhecimento das indicações geográficas de alimentos e bebidas brasileiras: regulamento de uso, delimitação da área e diferenciação do produto.

Ciência Rural, [s.l.], v. 43, n. 7, p. 1.330-1.336, 2013. DOI: https://doi.org/10.1590/S010384782013005000076.

VIEIRA, A. C. P. et al. A Indicação Geográfica como instrumento para o desenvolvimento de uma região: caso Indicação de Procedência do "Vales da Uva Goethe" - SC. Revista de Propriedade Intelectual - Direito Contemporâneo e Constituição PIDCC, [s.l.], v. 3, n. 5, p. 407-425, 2014.

\section{Sobre os Autores}

\section{Márcio Nannini da Silva Florêncio}

E-mail:marcio_nannini@hotmail.com

Mestre em Ciência da Propriedade Intelectual pela Universidade Federal de Sergipe em 2018.

Endereço profissional: Av. Marechal Rondon, s/n, Jardim Rosa Elze, São Cristóvão, SE. CEP: 49100-000.

\section{Maraiza Santana dos Santos}

E-mail: mara.iza.santana@hotmail.com

Mestre em Ciência da Propriedade Intelectual pela Universidade Federal de Sergipe em 2015.

Endereço profissional: Av. Marechal Rondon, s/n, Jardim Rosa Elze, São Cristóvão, SE. CEP: 49100-000.

\section{Francisco Sandro Rodrigues Holanda}

E-mail: fholanda@infonet.com.br

Pós-Doutor em Agronomia pela Universidade de Wisconsin (EUA) e doutor em Agronomia pela Universidade Federal de Lavras em 1996.

Endereço profissional: Av. Marechal Rondon, s/n, Jardim Rosa Elze, São Cristóvão, SE. CEP: 49100-000.

\section{Antonio Martins de Oliveira Júnior}

E-mail: amartins.junior@gmail.com

Doutor em Engenharia Química pela Universidade Federal do Rio de Janeiro em 2006.

Endereço profissional: Av. Marechal Rondon, s/n, Jardim Rosa Elze, São Cristóvão, SE. CEP: 49100-000. 